\title{
Activity in Social Media and Intimacy in Social Relationships
}

Alistair G. Sutcliffe

University of Manchester

Jens F. Binder

Nottingham Trent University

Robin I.M. Dunbar

University of Oxford

PRE-PUBLICATION VERSION

IN PRESS WITH COMPUTERS IN HUMAN BEHAVIOR 


\section{Abstract}

We investigated associations between online and offline socialising and groups of social ties as postulated by the Social Brain Hypothesis (SBH). An online survey of social media use, social satisfaction and loneliness generated 249 complete responses from a sample of staff and students at the University of Manchester. Regression-based analyses showed that offline social activities and social time were positively associated with size of a core support group and social satisfaction. In contrast, social media time was positively associated with social satisfaction and the size of the total network, while the number of online contacts was positively related to social satisfaction, size of a wider sympathy group and total network size. No effect for loneliness was found. The number of ties reported for each SBH group was similar to that in previous studies. The more intimate support group ( 5) appears to be more closely connected with offline social activities, whereas social media use and contacts influence the less intimate sympathy group $(\sim 15)$ and total network $(\sim 150)$. These findings provide further support for functional differences between different layers of closeness in personal networks, and they help us in further defining the boundaries of relationship enhancement via communication technology.

Keywords: social relationships; social media use; strong/weak ties; social satisfaction; social brain hypothesis 


\section{Introduction}

Individuals often use social media to seek and obtain social support (Ellison, Steinfield \& Lampe, 2011; Wright \& Bell, 2003); however, the nature of the support afforded by social media may vary according to the intensity of relationships. Several studies have suggested that levels of social support are related to emotional closeness in social relationships and that intensity of social media use is related to the degree of intimacy in relationships (Ellison, Steinfield \& Lampe, 2007, 2011; Lampe et al., 2006; Hsu, Wang \& Yi-Tang, 2011). For example, intensity of social media use has been demonstrated to facilitate emotional support (Baker \& Moore, 2008; Greenhow \& Robelia, 2009) and perceived social support (Kim \& Lee, 2011). Oh, Ozkaya and LaRose (2014) reported that an increased number of Facebook friends improved positive affect and social satisfaction among college students. However, other studies have reported contrasting results. For example, Pollet, Roberts and Dunbar (2011) found that use of social media did not enhance emotional closeness to friends or lead to larger offline social networks. Real world (offline) social networks and Facebook networks show a high degree of overlap (Ellison et al., 2007; Subrahmanyam et al., 2008) and the consensus from several studies is that Facebook in particular, and social media more generally, supplement rather than supplant offline social relationships (Wellman et al., 2001; Haythornthwaite 2002, Kraut et al., 2002; boyd \& Ellison, 2007; Ellison et al., 2007; Ellison et al., 2007; Burke \& Kraut, 2014). However, few studies have attempted to differentiate between the social structure (i.e. best, close and other friends) in an individual's social network and how social support may vary between different types of relationship (Zhang \& Leung, 2015). Further, previous findings have cast doubt on an ad hoc model that ascribes highest levels of support to the strongest online relationships (Burke \& Kraut, 2013).

Large-scale surveys with representative samples have demonstrated that strong ties (close friends) experience more Internet communication and social support than weak ties for North American (Boase et al., 2006) and Slovenian Internet users (Hlebec, Manfreda \& Vehovar, 2015). While the association between social media use, provision of social support and emotional closeness in relationships has been established, it is less clear whether these relationships are linear or differentiated according to layers of intimacy, as posited in psychological theories of friendship (Hays, 1984; Oswald, Clark \& Kelly, 2004; Sutcliffe,

Dunbar, Binder \& Arrow, 2012).

\subsection{An Evolutionary Account of Social Media Activity and Relationship Strength}

Commented [J B1]: I am still struggling a bit with finding my way through the intro. Here is a suggestion:

Insert two sub-headings, 1.1 and 1.2 , that bring back some of the distinction between our theoretical perspective and wider work. Cut one paragraph as indicated below that does not address functional differences between ties at all. 
Dunbar's Social Brain Hypothesis (SBH) (1998) asserts that we may naturally form only a small number of very close friendships (the support group $\sim 5$ ), with more good friends (sympathy group 12-15) and about 150 in our active social network of friends and acquaintances (defined as all individual ties with contact frequency of more than once year and a genuine personal relationship; Hill \& Dunbar, 2003). Studies operating within the SBH framework have assigned different functional definitions to support group ties, as best friends from whom ego would first seek help in times of crisis, and sympathy ties, as good friends who are contacted at least monthly (Dunbar \& Spoors, 1995; Dunbar, 1998) and whose death would leave you personally devastated (Buys \& Larson, 1979). Support for functional differences between inner network layers was found by Binder, Roberts and Sutcliffe (2012), such that socialising needs were more strongly satisfied by the sympathy group, whereas intimacy needs were more strongly met by the support group. Further, Roberts et al. (2009) found a negative relationship between active network size and mean emotional closeness between ego and others in their network, suggesting that time and cognitive constraints may result in a trade-off between the number of relationships in the network, and their emotional intensity.

Social networks are generally held to consist of relationships with different levels of intensity or emotional closeness. Oswald and colleagues (2004; see also Oswald \& Clark, 2006) developed a measure of friendship maintenance behaviours consisting of positivity, supportiveness, openness and interaction (i.e. joint activities) and these dimensions reliably distinguished between close and casual friends (Oswald et al., 2004). The quality and duration of friendships depend on the frequency and quality of maintenance activities (Hays, 1984, 1989; Oswald et al., 2004). Wellman and Wortley (1990) distinguished between strong ties (those you feel closest to outside your home) with a median size of four, and significant ties (those who are in touch with you in your daily life and who are significant in your life) with a median size of seven. Similarly, a Pew Social Ties Survey (Boase et al., 2006) separated core from significant ties. However, although the distinction between strong and weak ties is established as a theoretical concept (Granovetter, 1973, 1983), the functions of different relationship intensities within personal social networks are less well understood.

Social interaction time has been posited as a fundamental constraint on the number of relationships we can manage (Dunbar, 1998, 2003; Hill \& Dunbar, 2003). Social media could alleviate this constraint by facilitating communication over space and time (Schwanen \& Kwan, 2008). Although some studies have shown that the total number of online friends is
Commented [J B2]: I have reworked this bit and cut the paragraph already identified further down. References can stay as is. 
much higher than the 150 posited by SBH as the limit of our social circle (Ellison et al., 2007; Wellman et al., 2001), others have demonstrated no difference between online and frequent social media use and offline social network size (Pollet et al., 2011; Dunbar et al., 2015). The issue here seems to be purely semantic. In the offline world, we readily distinguish between friendships of different quality (intimate friends, best friends, good friends, just friends, acquaintances, etc.) that correspond to the layers identified in personal social networks (Dunbar, 2017). Social media platforms do not normally make these distinctions (even though their users may do so); instead, they allow users to include network layers (e.g. acquaintances) that would not normally be counted as 'friends' in the strict sense. In fact, exactly the same relationship layers as are found in offline personal social networks are present in online platforms and are defined by exactly the same frequencies of interaction as define them in the offline world (Dunbar et al., 2015).

1.2 Convergent Evidence for Functional Differences Among Online Relationships

In this section, we outline previous work that has not made use of the SBH framework, yet addresses functional differences between online ties at different levels of intimacy. As will become clear there is convergent evidence for such differences in line with our theoretical perspective.

In a factor analysis of survey data on several motivations for Internet use, Walther and boyd (2002) note that perceived benefits may favour weaker ties (in the sense of Granovetter, 1983), as increased social distance extends the range of expertise for advice, lowers the risk of social embarrassment and less intimacy may encourage more candor. However, their study focussed on e-communities and email use rather than social media. Baym, Zhang and Lin (2004) investigated the effect of distance on relationship maintenance by computer-mediated communication, showing that students preferred face-to-face interaction with local relationships, whilst maintaining their distance relationships through the Internet and the telephone. Although the students also used the Internet for close relationships, more intimate exchanges were carried out face-to-face or through telephone calls

Intensity of Internet use has been shown to correlate positively with the number of friends in an individual's social network (Wellman et al., 2001; Kraut et al., 2002); while Ellison et al. (2007) found that intensity of Facebook use was positively related to different forms of social capital which may reflect social relationships, although they reported general estimates of the social capital rather than absolute numbers of relationships. Ellison et al.
Commented [J B3]: Have inserted this as a mere guiding and structuring device. Only works if the paragraph above gets cut. 
(2007) showed that Facebook was mainly used to establish contact among people who were already friends. Friendship maintenance appears to be the most common motivator for SNS use (Joinson, 2008), although forming new social relationships may also play a role. Real world (offline) social networks and Facebook networks show a high degree of overlap (Ellison et al., 2007; Subrahmanyam et al., 2008) and the consensus from several studies is that Facebook in particular and social media more generally supplement rather than supplant offline social relationships (Wellman et al., 1981; Kraut et al., 2002; Ellison et al., 2007; Valkenburg \& Peter, 2007).

Social networks are an important source of support for people, both materially and emotionally. Individuals with low levels of social support have higher levels of morbidity and mortality, especially from cardiovascular disease (House, Landis \& Umberson, 1988; Uchino, 2006). The link between loneliness and the size, density and quality of ties in social networks has been established by several studies (Russell, Peplau \& Cutrona, 1980; Sarason et al., 1987). Individuals often use social media to seek and obtain social support (Ellison et al., 2011; Wright \& Bell, 2003); however, the nature of support afforded by social media may vary according to the intensity of relationships. Rozzell et al. (2014) in a Facebook 'likes' study, found that social support from weak ties was more prevalent in overall frequency, although responses from strong ties were perceived to be more supportive. Similarly, strong ties were perceived as providing more emotional and informational support than weak ties, in a study of SNS use (Kreamer et al., 2014). The importance of strong ties in providing social support via social media has also been noted by Rains and Keating (2011) and Wright and Miller (2010).

Donath and boyd (2004) proposed that forming and maintaining weak relationships is a prime motivator for social media communication, and this claim has been supported in subsequent SNS studies (e.g. Steinfield, Ellison, \& Lampe, 2008; Wright \& Miller, 2010). As many users have hundreds of Facebook 'friends' (Tong et al., 2008), not surprisingly, weak ties dominate SNSs in overall volume of contacts. Facebook is used to obtain new and diverse information or perspectives, a function associated with weak ties (Ellison et al., 2011; Smock et al., 2011). Weak ties play an important supportive role, especially in health communication, which may be explained by the perceived reduction in intrusiveness and increased objectivity of advice from less intimate relationships (Wright, Raines and Banas, 2010). This interpretation supports Granovetter's (1973) assertion that social support is primarily derived from many weak ties with individuals who can fulfil diverse needs. Weak 
tie support may reflect greater heterogeneity among alters than strong ties, thereby facilitating more diverse support for a wider range of problems (Adelman, Parks \& Albrecht, 1987). Furthermore, weak ties may be better suited to providing social support than strong ties, with feedback being more objective, given their reduced intimacy (Adelman et al., 1987). Weak ties may also enable more informed comparison than information obtained from fewer, strong ties (Helgeson \& Gottlieb, 2000). Wright et al. (2010) noted that weak ties have fewer relationship obligations than strong ties, potentially reducing the discomfort from communicating negative or sensitive information.

Evidence for the importance of strong ties as sources of social support is generally more prevalent than for weak ties, and several studies have concluded that strong ties are the prime providers of support in social networks (Rains \& Keating, 2011; Wright \& Miller, 2010, Albrecht \& Goldsmith, 2003). Blight, Jagiello and Ruppel (2015) found that close friends online provided more than twice (68\%) the volume of emotional and social support than weak ties (32\%). Social support from online close friends has been associated with reduced loneliness (Lee, Noh \& Koo, 2013) and improving social satisfaction (Trepte, Dienlin \& Reinecke, 2016). Wellman and Gulia (1999) noted that strong ties can be maintained online as well as offline, citing the affordances of social media and CMC (computer-mediated communication) tools in facilitating individuals' access to strong ties for social support.

The contrasting evidence on relationships' role and social support may reflect the role of strong ties in providing intimate emotional and social support; whereas weaker relationships may be a source of support for more diverse information and advice. Weak tie connections in Facebook tend to provide bridging social capital, rather than bonding social capital that is likely to provide social support (Ellison et al., 2007). Although the average number of Facebook friends mirrors the total size of offline social networks (Dunbar et al., 2015; Dunbar, 2015), intensity of use (Ellison et al., 2007) and social support may not be equally distributed among alters in an individual's network. These questions motivated our study on the relationships between social media activity, the outcomes of social support measured in terms of satisfaction and loneliness, and different relationship types in an individual's social network. 


\subsection{Hypotheses}

We investigated the general research question "Is social media activity related to layers in intimacy?” using Dunbar’s Social Brain Hypothesis (1998) which proposes a social structure consisting of three layers with decreasing levels of intimacy:

(i) the support group: closest intimates, typically immediate family members and best friends, who provide emotional and behavioural (e.g. financial) support, "people you would seek advice, support or help from in times of severe emotional or financial crisis”

(ii) sympathy group: reliable friends, whom one can depend on in reciprocal relationships (e.g. friendship in the social sense, protection against harassment, social alliances, distributed childcare), "people whose death would leave you personally devastated",

(iii) active social network: total number of active social relationships, all individual ties with contact frequency of more than once year and a genuine personal relationship, i.e. friends and acquaintances, (includes support and sympathy groups)

The objective of our study was to investigate the effect of social activity and social media use on the size of SBH-like social network layers, social satisfaction and loneliness. While previous research suggests that network layers may be differently associated with online behaviours, we start this investigation with a number of general expectations that will help to bring out any such differential patterns. Specifically, social activities, social time, social media use and social media contacts were used as predictors to test five hypotheses, each associated with four sub-hypotheses relating to (a) social media time, real world off line, (b) social activity, real world off line, (c) social media use (on line) and (d) social media contacts (on line):

H1 Increased (a) social time, (b) social activity, (c) social media use and (d) more social media contacts will be associated with larger overall social networks.

H2 Increased (a) social time, (b) social activity, (c) social media use and (d) more social media contacts will be associated with larger sympathy groups in social networks. 
H3 Increased (a) social time, (b) social activity, (c) social media use and (d) more social media contacts will be associated with larger support groups in social networks.

H4 Increased (a) social time, (b) social activity, (c) social media use and (d) more social media contacts will be associated with higher levels of social satisfaction and lower levels of loneliness.

H5 Increased social satisfaction and lower loneliness will be associated with larger social networks, larger sympathy and support groups.

Possible effects of the number of distant relationships, presence of long-term partner, and gender were also investigated.

\section{Method}

\subsection{Sample}

A total of 339 participants, students and staff at the University of Manchester, UK, responded to an online survey. However, 90 of these (26.5\%) failed to complete all the questions, and the analyses reported here were therefore based on the 249 complete response sets obtained. The mean age of the participants was 20.9 years $(S D=3.6)$ with $91 \%$ of participants falling into the range 18 to 25. Most respondents (94\%) were undergraduate or postgraduate students and $71 \%$ held UK nationality. The majority of participants were female (64\%), and $45 \%$ of respondents reported that they had a long-term partner or serious romantic relationship.

\subsection{Measures and Procedure}

The survey questionnaire consisted of 28 questions organised in seven sections: participant demographics, social networks, social time/activities, SNSs/CMC time, group activity, social satisfaction and loneliness, and spatial proximity of best friends and kin. The survey was advertised for 20 days to staff and students using the University of Manchester online survey application (Qualtrics). The sections of the survey were organised as follows:

Demographics. These included age, gender (coded as 0 for male and 1 for female), employed/student, nationality, permanent partner/spouse yes/no.

Social networks. Participants' social networks were identified with questions designed to elicit the number of social ties by categories of emotional closeness based on SBH which proposes three layers in order of decreasing emotional intensity, referred to as the support ( $\sim 5$ 
alters), sympathy ( 15) and weak ties (total ties: 150) groups (see Sutcliffe et al., 2012). Following Roberts et al. (2009) and Binder et al. (2012), three separate cues elicited the support group ("the number of people from whom you would seek advice, support or help in times of severe emotional or financial crisis"); the sympathy group ("the number of people whose death you would find personally devastating”); and finally the total number of friends and social acquaintances for whom an active tie existed. Participants were instructed to think of the total of their social network, which could include both offline and online contacts.

Social time/activities. This section consisted of two parts: first, estimates of the hours spent on free-time socialising, work/study-related activities, or a mix of social and work activities were elicited, for weekdays and weekends in each case. The second part elicited frequencies of social activities (gossip, gathering, sport and hobbies) on a 1-5 scale ranging from very rarely to very often.

Social media technology use. Estimates of the number of people contacted and hours spent using eight communication technologies in the last seven days were elicited: for landline phones, e-mail, social networking sites, mobile phone calls, mobile phone text messages, instant messaging/chat, other Internet socialising (e.g. Twitter, multiplayer games) and conventional letters. An estimate of total Internet hours was also included.

Social satisfaction and loneliness. Four social satisfaction questions, adapted from Diener et al. (1985), were rated on a 1-5 scale: "In most ways my social life is close to my ideal”, "I am satisfied with my social life", "So far I have got the important things I want in my social life" and "If I could live my social life again, I would change almost nothing”. Since the scale had a high internal reliability (Cronbach's $\alpha=.91$ ), all items were averaged to form a composite index for social satisfaction. Two questions (using 1-5 scales) eliciting social and emotional loneliness were taken from Binder et al. (2012): loneliness stemming from not belonging to any group, and not having an intense relationship with others.

Socio-spatial proximity. Respondents were asked the distance between themselves and their three best friends and closest kin on a six-part scale based on travel time, ranging from 10 minutes to over 3 hours.

The following aggregate variables were created for analysis:

Social satisfaction: average of the four questions on the social satisfaction scale. 
Total social time: (social (weekday) + social (weekend) + mixed (weekday) + mixed (weekend)) / $2^{1}$.

Total social activities: average of ratings for the four social activities (gossip, gatherings, sports and hobbies).

Total social media time: average total time for e-mail, SNS, mobile phone, mobile SNS, IM and other Internet.

Total social media contacts: average total contacts for e-mail, SNS, mobile phone, mobile SNS, IM and other Internet.

Total SBH network: average total of estimates for the three-layer questions (support, sympathy groups and all ties).

Distance index: average total of three relatives and three friends rating on a six-point distance scale, where $1=<10$ minutes and $6=>3$ hours.

The social network, social time, social media time and contacts variables all had skewed distributions so these variables were log transformed for statistical analysis. Relationships between the variables stated in the hypotheses were investigated by hierarchical regression tests, while intergroup differences (e.g. genders, etc.) were investigated by t-tests for independent samples.

\section{Results}

3.1 Social networks

The support group size agreed well with the predictions of SBH, although the sympathy group and total network sizes were somewhat larger than predicted (albeit within the range reported by previous studies in both cases). Observed group sizes were not, however, significantly different from SBH expected group sizes (5 for the support group, 15 for the sympathy group, 150 for the total network; $z$ tests, $z=0.24, z=0.27, z=0.07$, all $p>.81$ ) (see Table 1). There were no significant gender differences.

\footnotetext{
1 This measure was divided by 2 to average across weekdays and weekends in order to obtain an index representing a daily mean.
} 


\begin{tabular}{lccc}
\hline $\begin{array}{l}\text { Network } \\
\text { layers }\end{array}$ & Total mean (SD) & Male & Female \\
\hline Support & $6.14(4.72)$ & 5.99 & 6.27 \\
Sympathy & $22.62(28.19)$ & 20.64 & 23.99 \\
Total network & $174.88(373.7)$ & 250.13 & 133.54 \\
\hline
\end{tabular}

TABLE 1. MEAN ESTIMATES OF FRIENDS IN SOCIAL NETWORK LAYERS

The total network for males was also higher than Dunbar's maximum socially active network ( 150), although this was within the range found in previous studies and was not significantly different overall from the expected value. The high mean may have been a consequence of answers to the question including acquaintances and other friends who were not socially active (i.e. address book acquaintances).

3.2 Social time and activities

Not surprisingly, the participants spent more time socialising at the weekend, although social interaction time and mixed social/work activity was similar for both weekdays and weekends (Pearson correlations, $p<0.01$ ). The social interaction figures appear to be quite high, perhaps because they reflect time in social company rather than direct interaction (see Table 2).

\begin{tabular}{lcc}
\hline Time (hours)/day & Weekday & Weekend \\
\hline Social activities & $7.75(3.72)$ & $8.74(4.0)$ \\
Work/study & $3.82(2.37)$ & $1.62(2.19)$ \\
Social & $3.95(2.44)$ & $6.76(3.72)$ \\
Mixed & $2.85(2.94)$ & $2.71(3.72)$ \\
\hline
\end{tabular}

TABLE 2. MEAN AND (STANDARD DEVIATION) OF SOCIAL/WORK TIME (HOURS/DAY)

Social activity times were slightly lower than the sum of social and mixed time, indicating that the respondents regarded some work-related interaction as social activity. There were no gender differences in social time apart from females spending more mixed social/work time than males during the week $(M=3.21$ vs. $M=2.33, t(222.3)=-2.39, p<.05)$. Presence of a long-term partner was associated with spending more time in social interaction ( $M=9.7$ vs. 
$M=7.9$ hours, $t(230.8)=3.70, p<.001)$ and social hours at weekends $(M=7.8$ vs. $M=5.8$ hours, $t(225.9)=4.37, p<.001)$.

Gossip and meeting with others were the most frequent social activities, with females being more active in gossip and social meetings while males rated their activity for sport and hobbies as more frequent (see Table 3).

\begin{tabular}{lcccc}
\hline & Means (SD) & Males & Females & $t(d f), p$ \\
\hline Gossip & $3.62(1.22)$ & 3.16 & 3.89 & $-4.48(162,2),<.001$ \\
Meeting & $3.30(1.15)$ & 3.09 & 3.41 & $-2.06(161.9),<.05$ \\
Sports & $2.14(1.30)$ & 2.44 & 1.99 & $2.64(159.4),<.05$ \\
Hobbies & $2.88(1.11)$ & 3.15 & 2.72 & $2.83(166.2),<.01$ \\
\hline
\end{tabular}

TABLE 3. MEAN AND (SD) FOR FREQUENCY RATINGS OF SOCIAL ACTIVITIES (1-5 SCALE, WHERE $5=$ VERY FREQUENT)

Presence or absence of a partner made no difference to social activities or group social time..

3.3 Use of communication media

Social networking sites (e.g. Facebook) were the most frequently used technology both in terms of hours and number of contacts made, followed by mobile text messaging, e-mail, mobile voice and chat (instant messaging), although the order of these varied by hours used and contacts (see Table 4).

\begin{tabular}{lcc}
\hline Technology & Mean contacts & Time (hours)/week \\
\hline SNS & $13.34(12.48)$ & $2.53(2.68) *$ \\
Text (SMS) & $10.72(8.64) *$ & $1.39(1.76)$ \\
E-mail & $7.49(10.16)$ & $1.23(2.22)$ \\
Mobile: voice & $6.73(7.31)$ & $1.13(1.70)$ \\
Chat (IM) & $5.01(9.26)$ & $1.54(4.22)$ \\
Internet other & $2.60(19.56)$ & $0.44(1.17) * *$ \\
Phone & $1.06(2.11)$ & $0.29(1.07)$ \\
Letter & $0.59(1.39)$ & $0.16(0.46)$ \\
\hline
\end{tabular}


TABle 4. MEAN AND (SD) FOR CONTACTS MADE AND HOURS SPENT ON EACH TECHNOLOGY IN THE LAST SEVEN DAYS. GENDER/PARTNER DIFFERENCES DENOTED AS * $P<.05, * * P<.01$

There were no gender differences in contacts made, while in time spent only SNS and other Internet showed differences, with females being more active in texting $(M=1.94$ vs. $M=$ 1.26, $t(241.2)=-2.51, p<.05)$ and males spending more Internet time $(M=1.63$ vs. $M=$ 0.73, $t(110.1)=3.26, p<.01)$. Long-term partners made no difference for hours spent and contacts made, apart from mobile texting where respondents without partners tended to make more contacts $(M=11.67$ vs. $M=9.32, t(241.8)=-2.17, p<.05)$.

Taking the total of social media (SNS, SMS and IM) time, the respondents spent 7.82 / 28.27 hours or $27.6 \%$ of their social time online, reflecting the lifestyle of our respondents, who were mainly students. The total contacts made via social media was 43.27 , which is closer to the sympathy group than to total network sizes, so it appears that the respondents may have been quite selective with their contacts, although we have no data on whether these were friends or strangers.

Overall the respondents were generally socially satisfied $(M=3.38, S D=0.97)$ and not lonely (for social loneliness $M=2.78, S D=1.30$, for emotional loneliness $M=2.85$, $S D=$ 1.45). There were no gender differences although, predictably, absence of a long-term partner did lead to increased emotional loneliness $\left(M_{\text {PRESENT }}=2.35, M_{\text {ABSENT }}=3.26, t(220.6)=\right.$ $5.05, p<.001)$.

3.4 Multivariate relationships

To investigate the hypotheses and further explore the relationship between social activity, loneliness social satisfaction and social networks, we carried out a set of hierarchical linear regression analyses. The social network dependent variables showed a non-normal distribution and were therefore log transformed. In the first step, gender and age were regressed as control variables. In the second and third steps, predictor variables were added to test the hypotheses that increased social activity and higher use of social media technology, will be associated with larger social networks, less loneliness and higher social satisfaction. The regressions were then repeated using aggregate social distance and presence of a longterm partner in step 1 to test for these possible effects.

Social activity and social networks. The control variables and social time had no effect on support group size, but social activity was significant (Regressions, $\mathrm{r}^{2} 0.103, \beta=.272, p<$ 
.00 ). Gender and social activity had effects on the sympathy group (for gender: $\beta=.136, p<$ .05 , for social activity: $\beta=.177, p<.05$ ), but there was no effect for social time. Social activity also had an effect on the total network size $(\beta=-.145, p<.01)$.

To test possible influences of loneliness and social satisfaction on network size, further regressions were run with the same step 1 control variables but adding these predictors in steps 2 and 3. Age and gender had a marginal effect for the sympathy group ( $p s<.05$ ) but the overall model was not significant; and no effect was found for these predictor variables on the support group or the total network. However, when the SBH groupings were used as predictors of satisfaction and loneliness, the size of the support group showed a positive association with satisfaction $(\beta=.244, p<.001)$, and a weaker negative association with loneliness ( $\beta=-.15, p<.05$ ), although the overall model was not significant. No effects were found for the sympathy group or the total network.

Social media and social networks. These regressions used the same age and gender control variables as social media time (step 2) and social media total contacts (step 3) to predict social network layer size. The support and sympathy group models were not significant; however, both social media time and contacts had an effect on the total network (for social media time $\beta=-.154, p<.05$, for social media contacts $\beta=.286, p<.001$ ). When distance and long-term partner were added to the model in step 1, only SM contacts had a positive effect on the support group ( $\beta=.163, p<.05$ ); no effect of any variables was found on the sympathy group, although distance, social media time and contacts all influenced the size of the total network (for distance $\beta=.143, p<.05$, for social media time $\beta=-.181, p<.01$, for social media contacts $\beta=.345, p<.001)$.

The effect of social media was tested using the same predictors with social time and social activities as dependent variables. Age and social media total contacts influenced social activity (for age $\beta=-.187, p<.01$, for social media contacts $\beta=.327, p<.001$ ), but there was no effect for social media time. Both social media time and contacts had a positive effect on social time (for social media time $\beta=.178, p<.05$, for social media contacts $\beta=.157, p$ $<.05)$.

Loneliness and social satisfaction. Gender and social activity had no effect on social satisfaction, although age had a negative effect $(\beta=-.164, p<.05)$. There was no effect of the control variables, social time or social activity on loneliness. Social activity but not social time predicted social satisfaction $(\beta=.355, p<.001)$. Social media time and total contacts 
predicted social satisfaction (for social media time $\beta=-.168, p<.01$, for social media contacts $\beta=.209, p<0.001$ ), but again there was no effect on loneliness. When the control variables were changed to long-term partner and distance, not surprisingly absence of a longterm partner increased loneliness $(\beta=.179, p<.05)$, but there was no effect of any of the variables on social satisfaction.

Summary Social time positively predicted social satisfaction and support group size; similarly, frequency of social activity had a positive association with support group size, social satisfaction and social media contacts, but also a weaker positive association with sympathy group size, and a negative relationship with the total network. Social media time had a weak positive relationship with social time and total network size, but had a weak, negative relationship with social satisfaction. The negative influence of social media time on satisfaction may reflect spending time on non-social activity, e.g. work-related communication or profile maintenance.

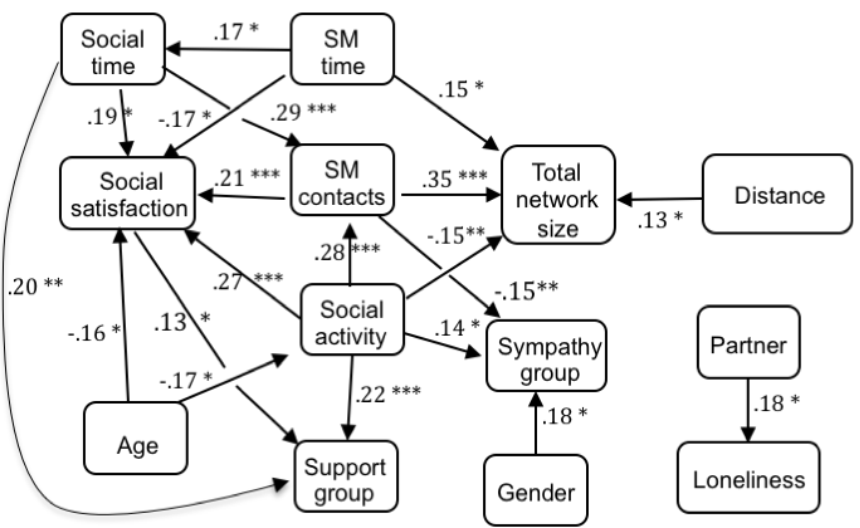

FIG. 1. Multivariate relationships: summary of regressions. Beta values and significance $(*<$ $.05, * *<.01, * * *<.001)$ are annotated on each relationship.

Social media contacts had positive relationships with all SBH network groupings, social satisfaction and social activity, which may reflect social media friends mirroring real-life relationships. Social satisfaction had a positive association with the support group, whereas no direct association with satisfaction or loneliness was found for the sympathy group or the total network. Gender, age and separation from friends played a relatively minor role. No associations were found for any of the variables with loneliness, apart from absence of a long-term partner. Possible differences in effect sizes for relationships between the SBH 
layers and other variables were tested where corresponding significant relationships had been detected in the regression analyses (e.g. Social Activity + Support/Total network, Sympathy/Total network; Social Time, SM contacts + Sympathy/ Total network). However, no significant differences were found following the procedure described in Paternoster et al. (1998).

\begin{tabular}{lccccc}
\hline $\begin{array}{l}\text { Hypothesis } \\
\text { predictor }\end{array}$ & $\begin{array}{c}\text { H1 Total } \\
\text { network }\end{array}$ & $\begin{array}{c}\text { H2 Sympathy } \\
\text { group }\end{array}$ & $\begin{array}{c}\text { H3 Support } \\
\text { group }\end{array}$ & $\begin{array}{c}\text { H4 Social } \\
\text { satisfaction }\end{array}$ & H5 Loneliness \\
\hline Social time & NS & NS & $* *$ & $*$ & NS \\
Social activity & $* * *$ & $*$ & $* * *$ & $* * *$ & NS \\
$\begin{array}{l}\text { Social media } \\
\text { use }\end{array}$ & $*$ & NS & NS & $* * *$ & NS \\
$\begin{array}{l}\text { Social media } \\
\text { contacts }\end{array}$ & $* *$ & $* *$ & NS & $*$ & NS \\
$\begin{array}{l}\text { H4 Social } \\
\text { satisfaction }\end{array}$ & NS & NS & $*$ & & \\
H5 Loneliness & NS & NS & NS & & \\
\hline
\end{tabular}

TABLE 5. SUMMARY OF HYPOTHESES AND RESULTS

\section{Discussion}

The status of all five hypotheses is summarised in Table 5. Discounting social time, H1 (on predicting total network size) was supported for all predictor variables. The association between social media contacts and the total offline network reflects the well-established finding that social media networks help to maintain real world social networks (Ellison et al., 2007; boyd \& Ellison, 2007), while the link between social media time agrees with previous studies demonstrating links between frequency of Internet and social media use and the number of friends in social networks (Wellman et al., 2001; Kraut et al., 2002). However, no association was found with social satisfaction, possibly indicating that the positive relationship between social support and intensity or frequency of social media use (Ellison et al., 2007, Carr, Wohn \& Hayes, 2016) may not translate into satisfaction.

Regarding H2 (on predicting sympathy group size), partial support was found for social activity and social media contacts, possibly reflecting the volume of social media friends who may be influenced by offline friends at this more intimate level. Again no association was found with satisfaction; however, comparing the sympathy group with evidence for strong ties providing social support (Wright \& Miller, 2010; Rains \& Keating, 
2011; Blight et al., 2015) is difficult since measures of strong ties in previous studies may overlap both sympathy and support groups in our study.

Regarding H3 (on predicting support group size), partial support was obtained with social time and activities influencing support group size, although there was no influence from contacts or social media time. The association with satisfaction and the support group may reflect the role of this group in provision of social support, supporting evidence for this role of close friends found in previous studies (Wright \& Miller, 2010; Blight et al., 2015; Carr et al., 2015), in contrast to the sympathy group.

Overall, the frequency of social activities appears to be the more important influence on social network size at the support, sympathy group and total network level, as well as influencing social satisfaction. In contrast, the role of online socialising and time spent on social media diminishes as network layers become populated with closer and more significant ties. At the level of the support group, the lack of influence of online variables we found complements the findings of Pollet et al. (2011), that social media time was not associated with larger offline social networks, or with emotional closeness. However, at the level of the sympathy group and the total network, social media contacts did show positive associations with layer sizes. In addition, online contacts contributed to social satisfaction. These findings support arguments for the importance of online friends, including strong ties, in the provision of social support (Carr et al., 2015; Blight et al., 2015). Time spent using social media, in contrast, is only associated with total social network size and social satisfaction. The latter finding possibly reflects the role of weak ties as well as strong ties in providing social support (Rozzel et al., 2014).

Regarding H4 (on predicting social satisfaction), support was found for both online socialising variables and overall socialising. This complements previous findings by $\mathrm{Oh}$ et al. (2014) on online networking and life satisfaction. In contrast, no effects were found in support of H5 (on predicting loneliness). This is in contrast to findings such as the ones by Pittman and Reich (2016) who found reductions in loneliness for specific social media activities such as image sharing on Instagram, but also confirms the wider perspective that the relationship between loneliness and social media use is difficult to ascertain (Song, Zmyslinski-Seelig, Kim, Drent, Victor, Omori, \& Allen, 2014). In addition, our measure of loneliness tried to differentiate between different types of loneliness and was not a general multi-item scale as used in most studies. Further, in our analyses loneliness did not emerge as 
simple the inverse of social satisfaction, and our study may simply reflect the fact that the two concepts are subject to different underlying psychological processes.

Overall, there was little effect of satisfaction and loneliness on SBH layer sizes, although social satisfaction positively predicted the support group size, consistent with the view that this layer is most closely associated with well-being (Sutcliffe et al., 2012). Lee et al. (2013) suggest that social media use can positively influence well-being, similar to our satisfaction findings, although they note that self-disclosure is an important mediator via social support for well-being. Distance was linked to the total network size, possibly reflecting the larger networks with increased distance (home and university friends) in our student population, although social media did not appear to mediate these relationships, in contrast to previous studies (Ledbetter, 2008).

The social networks we found are somewhat smaller than the network sizes reported in previous SNS studies (Ellison et al., 2007), although the numbers of good and best friends were similar to those reported in real-world studies (Hays, 1984, 1989). The number of best friends (i.e. support group) online and offline approximates to the theoretical predictions from SBH (Dunbar, 1998, 2003; Hill \& Dunbar, 2003) ( 5-6 predicted; we found 6-9); however, in the sympathy group (good friends), the numbers are somewhat higher than predicted (15 predicted versus 22.6 observed). Nevertheless, our findings are within the range in SBH layers found in large-scale surveys (Dunbar, 2015).

Focusing on our variables of online socialising, the frequency or extent of social media use had only a minor effect on SBH layers and satisfaction; in contrast, the number of social media friends did influence the total network and social satisfaction. Positive influences of Facebook friends on social satisfaction have been reported by Oh et al. (2014) and Nabi, Prestin and So (2013), although both these studies note that satisfaction was mediated by supportive interaction. Social media use and well-being also differ between cohorts in studies on students (Kalpidou, Costin \& Morris, 2011). The comparatively weak association between social media and social satisfaction we found agrees with the general finding that frequency of Internet use is at best only weakly related to perceived positive social outcomes (Kraut et al., 2002; Huang, 2010). Burke and Kraut's (2016) study on Facebook use and social support also confirms that weak ties only provide limited social support, whereas strong ties play an important role in wellbeing, which included social satisfaction and support in their study. 
In sum, we found a strong direct association between social group sizes as defined in SBH layers of intimacy with social activity and social media contacts. We interpret these findings as social friends reflecting real-world social structures, whereas actual use of social media is only associated with the overall social network and satisfaction. Social satisfaction appears to have a weak relationship to social group size, possibly because group size is a longer-term measure of social interaction, in contrast to satisfaction measures which may be more prone to short-term fluctuations.

At the same time, it is important to highlight a number of indirect associations between our online socialising variables and the network layers. In fact, both the time spent on social media and the number of online contacts are related to all network layers, either directly or through their contribution to overall time spent on socialising and social satisfaction (see Figure 1). This suggests again, that effects of online behaviours are rarely straightforward, but are more likely to work via mediating processes. Clearly, this is an area for ongoing research.

Studies on the effects of CMC on social ties, in HCI, Communication Studies and Psychology, have been dominated by a focus on close friends or, less commonly, overall networks. Research has rarely considered the possibility that networks may in fact be highly structured, with very distinct and characteristic layers of the kind identified by the SBH and this study. These layers have been documented widely in many aspects of human offline social networks and the structure of organisations, as well as in the online gaming world (see Fuchs et al., 2014). They appear to be remarkably robust, with their sizes, contact frequencies and emotional ratings varying only to a very limited extent across studies and environments. Previous studies of offline networks suggest that these layers are associated with very different kinds of functions and benefits to the individual. The support clique provides emotional and social support (especially in times of crisis), whereas the sympathy group seems to provide more generic social functions (regular social friends) while the network as a whole provides an extended network for the exchange of social information and generalised support) (Lehmann et al. 2014; Roberts et al. 2014). Our findings indicate that network layers are systematically linked to both offline and online socialising and that some of the effects of online socialising may manifest themselves only via the effect on offline, face-to-face socialising. It is this blend of online and offline activity that is most likely to carry explanatory power in the study of our social lives. Further, it seems likely that analyses of technology effects in HCI and neighbouring disciplines would benefit significantly by taking 
note of these findings. Beyond this, one obvious implication for social media design may lie in providing further facilities for structuring relationship networks in different layers of contacts associated with communication facilities customised according to emotional intensity.

The conclusions of this study are limited by the cross-sectional survey design, a modest response rate (73.5\%) and a convenience sample limited to staff and students, in contrast to longitudinal studies of social media use (Steinfield et al., 2008). In this respect, our sample represents a particular sub-population, but it is one that has the advantage of being especially likely to be active on the internet and social media. Cross-sectional studies of this kind have been frequently used to assess network size and structure sampled at a given moment in time. Our concern is not with the total number of individuals with whom a participant has interacted over a period of time, but rather with their perception of who forms their network at a given moment. Individual members may come and go over time, and the student age group, in particular, can have a very high turnover in network membership over relatively short periods of time (Saramäki, et al. 2014). The differences between our measure of social media activity, which follows Burke, Marlow \& Lento (2010), and other metrics such as intensity of use (Ellison et al., 2007; Zhang and Leung 2015) limits comparison with these studies; although our findings broadly agree that social media use mirrors the structure of off line social relationships. Comparison is also hindered by differences in social satisfaction and loneliness measures, where the scale used by Pittman and Reich (2016) may be a more appropriate choice. The classification of ties we adopted was motivated by Dunbar's SBH, so this was bound to introduce some incompatibility with the many previous interpretations of close friends, strong and weak ties (Granovetter, 1983; Wellman et al., 1981; Hays, 1989). However, it appears that the support group may be comparable with other investigations using strong ties.

For future work, it would be promising to add data on feature use in social media, which clearly vary between simple 'like' semaphores and more content-rich status updates (Blight et al., 2015; Pittman \& Reich, 2016), and to analyse the content of social support (Rozzell et al., 2014). This would broaden out an investigation of the associations between relationships at each SBH layer with not only social satisfaction but also how social media are used. 


\section{References}

Adelman, M. B., Parks, M. R., \& Albrecht, T. L. (1987). Beyond close relationships: Support in weak ties. In T. L. Albrecht \& M. B. Adelman (Eds.), Communicating social support (pp. 126-147). Newbury Park, CA: Sage.

Albrecht, T. L., \& Goldsmith, D. J. (2003). Social support, social networks, and health. In T. Thompson (Ed.), Handbook of health communication (pp. 263-284). Mahwah, NJ: Lawrence Erlbaum Associates Inc.

Baker, J. R., \& Moore, S. M. (2008) Distress, coping, and blogging: Comparing new MySpace users by their intention to blog. Cyberpsychology, Behavior, and Social Networking, 11(1), 81-85.

Baym, N. K., Zhang, Y. B., \& Lin, M. C. (2004). Social interactions across media. New Media and Society, 6, 299-318.

Binder, J., Roberts, S., \& Sutcliffe, A. G. (2012). Closeness, loneliness, support: Core ties and significant ties in personal communities. Social Networks, 34 (2), 206-214.

Blight, M. G., Jagiello, K., \& Ruppel, E. K. (2015). “Same stuff different day”: A mixed method study of support seeking on Facebook. Computers in Human Behavior, 53, 366373. http://dx.doi.org/10.1016/j.chb.2015.07.029.

Boase, J., Horrigan, J. B., Wellman, B., \& Rainie, L. (2006). The strength of internet ties. Washington D.C.: Pew Internet \& American Life Project.

boyd, D., \& Ellison, N. B. (2007). Social network sites: Definition, history, and scholarship. Journal of Computer-Mediated Communication, 13(1), 210-230.

Burke, M., \& Kraut, R. (2013). Using Facebook after losing a job: Differential benefits of strong and weak ties. In Proceedings of the 2013 Conference on Computer Supported Cooperative Work (pp. 1419-1430). New York: ACM Press.

Burke, M., \& Kraut, R. E. (2014). Growing closer on Facebook: Changes in tie strength through social network site use. In Proceedings of the SIGCHI Conference on Human Factors in Computing Systems (pp. 4187-4196). New York: ACM Press.

Burke, M., \& Kraut, R. E. (2016). The relationship between Facebook use and well-being depends on communication type and tie strength. Journal of Computer-Mediated Communication, 21(4), 265-281.

Burke, M., Marlow, C., \& Lento, T. (2010). Social network activity and social well-being. In: Proceedings of the SIGCHI Conference on Human Factors in Computing Systems. New 
York: ACM Press.

Buys, C. J., \& Larson, K. L., 1979. Human sympathy groups. Psychological Reports, 45, 547-553.

Carr, C. T., Wohn, Y. D,. \& Hayes, R. A. (2016). As social support: Relational closeness, automaticity, and interpreting social support from paralinguistic digital affordances in social media. Computers in Human Behavior, 62, 385-393.

Diener, E. D., Emmons, R. A., Larsen, R. J., \& Griffin, S. (1985). The satisfaction with life scale. Journal of Personality Assessment, 49(1), 71-75.

Donath, J., \& Boyd, D. (2004). Public displays of connection. BT Technology Journal, 22, 71-82.

Dunbar, R. I. M. (1998). The Social Brain Hypothesis. Evolutionary Anthropology, 6, 178190.

Dunbar, R. I. M. (2003). The social brain: Mind, language, and society in evolutionary perspective. Annual Review of Anthropology, 32, 163-181.

Dunbar, R. I. M. (2015). Do online social media cut through the constraints that limit the size of offline social networks? Royal Society Open Science, 3, 150292, http://dx.doi.or/10/1098/rsos.150292

Dunbar, R. I. M. (2017). The anatomy of friendship. Trends in Cognitive Sciences, 22, 32-51.

Dunbar, R. I. M., \& Spoors, M. (1995). Social networks, support cliques, and kinship. Human Nature, 6, 273-290.

Dunbar, R.I.M., Arnaboldi, V., Conti, M., \& Passarella, A. (2015). The structure of online social networks mirrors those in the offline world. Social Networks, 43, 39-47.

Ellison, N. B., Steinfield, C., \& Lampe, C. (2007). The benefits of Facebook “friends”: Social capital and college students' use of online social network sites. Journal of Computer Mediated Communication, 12, 1143-1168.

Ellison, N. B., Steinfield, C., \& Lampe, C. (2011). Connection strategies: Social capital implications of Facebook-enabled communication practices. New Media and Society, 13, 873-892. http://dx.doi.org/10.1177/1461444810385389

Fuchs, B., Sornette, D., \& Thurner, S. (2014). Fractal multi-level organisation of human groups in a virtual world. Scientific Reports, 4, 6526.

Granovetter, M. S. (1973). The strength of weak ties. American Journal of Sociology, 78, 1360-1380.

Granovetter, M. S. (1983). The strength of weak ties: A network theory revisited. Sociological Theory, 1, 201-233. 
Greenhow, C., \& Robelia, B. (2009) Old communication, new literacies: Social network sites as social learning resources. Journal of Computer-Mediated Communication, 14(4), 11301161.

Hays, R. B. (1984). The development and maintenance of friendship. Journal of Social and Personal Relationships, 1, 75-98.

Hays, R. B. (1989). The day-to-day functioning of close versus casual friendships. Journal of Social and Personal Relationships, 6, 21-37.

Haythornthwaite, C. (2002). Strong, weak, and latent ties and the impact of new media. Information Society, 18, 385-401. http://dx.doi.org/10.1080/01972240290108195

Helgeson, V. S., \& Gottlieb, B. H. (2000). Support groups. In S. Cohen, L. G. Underwood, \& B. H. Gottlieb (Eds.), Social support measurement and intervention: A guide for health and social scientists (pp. 221-245). New York, NY: Oxford University Press.

Hill, R. A., \& Dunbar, R. (2003). Social network size in humans. Human Nature, 14, 53-72.

Hlebec, V, Manfreda, K.L. \& Vehovar, V. (2015). The social support networks of internet users. New Media \& Society, 8(1), 9-32.

House, J. S., Landis, K. R., Umberson, D. (1988). Social relationships and health. Science, 241, 540-545.

Hsu, C.W., Wang, C.C., \& Yi-Ting, T. (2011).The closer the relationship, the more the interaction on Facebook? Investigating the case of Taiwan users. Cyberpsychology, Behavior, and Social Networking, 14,(7-8), 473-476. DOI: 10.1089/cyber.2010.0267

Huang, C. (2010). Internet use and psychological well-being: A meta-analysis.

Cyberpsychology, Behavior, and Social Networking, 13(3), 241-249. DOI: 10.1089=cyber.2009.0217

Joinson, A. N. (2008). ‘Looking at', ‘looking up’ or 'keeping up with’ people? Motives and uses of Facebook. In Proceedings CHI 2008, (pp. 1027-1036). New York: ACM Press.

Kalpidou, M., Costin, D., \& Morris, J. (2011). The relationship between Facebook and the well-being of undergraduate college students. Cyberpsychology, Behavior, and Social Networking, 14(4), 183-189. DOI: 10.1089/cyber.2010.0061

Kim, J. \& Lee, J. R. (2011) ,The Facebook paths to happiness: Effects of the number of Facebook friends and self-presentation on subjective well-being. Cyberpsychology, Behavior, and Social Networking, 14(6), 359-364.

Kraut, R., Kiesler, S., Boneva, B., Cummings, J., Helgeson, V., \& Crawford, A. (2002). Internet paradox revisited. Journal of Social Issues, 58(1), 49-74. 
Kreamer, N. C., Rosner, L., Eimler, S. C., Winter, S., \& Neubaum, G. (2014). Let the weakest link go! Empirical explorations on the relative importance of weak and strong ties on social networking sites. Societies, 4, 785-809. http://dx.doi.org/10.3390/soc4040785.

Lampe, C., Ellison, N., \& Steinfield, C. A. (2006). A Face(book) in the crowd: Social searching vs. social browsing. Proceedings: CSCW-2006, (pp. 167-170). New York: ACM Press.

Ledbetter, A. M. (2008). Media use and relational closeness in long-termfriendships: Interpreting patterns of multimodality. New Media and Society,10, 547-564. http://dx.doi.org/10.1177/1461444808091224.

Lehmann, J., Lee, P.C. \& Dunbar, R.I.M. (2014). Unravelling the evolutionary function of communities. In: R.I.M. Dunbar, C. Gamble \& J.A.J. Gowlett (eds) Lucy to Language: the Benchmark Papers, pp. 245-276. Oxford: Oxford University Press.

Lee, K-T., Noh, M-J., \& Koo D-M. (2013). Lonely people are no longer lonely on social networking sites: The mediating role of self-disclosure and social support. Cyberpsychology, Behavior, and Social Networking, 413-418.

Nabi, R.L., Prestin, A., \& So, J. (2013). Facebook friends with (health) benefits? Exploring social network site use and perceptions of social support, stress, and well-being. Cyberpsychology, Behavior, and Social Networking, 16(10), 721-727. DOI: 10.1089/cyber.2012.0521

Oh, H. J., Ozkaya, F., \& LaRose, R. (2014). How does online social networking enhance life satisfaction? The relationships among online supportive interaction, affect, perceived social support, sense of community, and life satisfaction. Computers in Human Behaviour, 30, 69-78.

Oswald, D. L., \& Clark, E. M. (2006). How do friendship maintenance behaviors and problem-solving styles function at the individual and dyadic levels? Personal Relationships, 13, 333-348.

Oswald, D. L., Clark, E. M., \& Kelly, C. M. (2004). Friendship maintenance: An analysis of individual and dyad behaviors. Journal of Social and Clinical Psychology, 23, 413-441.

Paternoster, R., Brame, R., Mazerolle, P., \& Piquero, A. (1998). Using the correct statistical test for equality of regression coefficients. Criminology, 36(4), 859-866.

Pittman, M., \& Reich, B. (2016). Social media and loneliness: Why an Instagram picture may be worth more than a thousand Twitter words. Computers in Human Behavior, 62, 155167. 
Pollet, T., Roberts, S. B. G., \& Dunbar, R. I. M. (2011). Use of social network sites and instant messaging does not lead to increased offline social network size, or to emotionally closer relationships with offline network members. Cyberpsychology, Behavior, and Social Networking, 14, 253-258.

Rains, S. A., \& Keating, D. M. (2011). The social dimension of blogging about health: Health blogging, social support, and well-being. Communication Monographs, 78, 511-534. http://dx.doi.org/10.1080/03637751.2011.618142

Roberts, S. B. G., Dunbar, R. I. M., Pollet, T., \& Kuppens, T. (2009). Exploring variations in active network size: Constraints and ego characteristics. Social Networks, 31, 138-146.

Roberts, S.B.G., Arrow, H., Lehmann, J. \& Dunbar, R.I.M. (2014). Close social relationships: an evolutionary perspective. In: R.I.M. Dunbar, C. Gamble \& J.A.J. Gowlett (eds) Lucy to Language: the Benchmark Papers, pp. 151-180. Oxford: Oxford University Press.

Rozzell, B., Piercy, C., Carr, C. T., King, S., Lane, B., Tornes, M., et al. (2014). Notification pending: Online social support from close and nonclose relational ties via Facebook.

Computers in Human Behavior, 38, 272-280. http://dx.doi.org/10.1016/j.chb.2014.06.006

Russell, D., Peplau, L. A., \& Cutrona, C. E. (1980). The revised UCLA loneliness scale: Concurrent and discriminant validity evidence. Journal of Personality and Social Psychology, 39, 472-480.

Saramäki, J., Leicht, E., López, E., Roberts, S.B.G., Reed-Tsochas, F. \& Dunbar, R.I.M. (2014). The persistence of social signatures in human communication. Proceedings of the National academy of Sciences, USA, 111, 942-947.

Sarason, B. R., Shearin, E. N., Pierce, G. R., \& Sarason, I. G. (1987). Interrelation of social support measures: Theoretical and practical implications. Journal of Personality and Social Psychology, 52, 813-832.

Schwanen, T., \& Kwan, M. P. (2008). The Internet, mobile phone and space-time constraints. Geoforum, 39(3), 1362-1377. http://doi.org/10.1016/j.geoforum.2007.11.005

Smock, A. D., Ellison, N. B., Lampe, C., \& Wohn, D. Y. (2011). Facebook as a toolkit: A uses and gratification approach to unbundling feature use. Computers in Human Behavior, 27, 2322-2329. http://dx.doi.org/10.1016/j.chb.2011.07.011.

Song, H., Zmyslinski-Seelig, A., Kim, J., Drent, A., Victor, A., Omori, K., \& Allen, M. (2014). Does Facebook make you lonely? A meta analysis. Computers in Human Behavior, 36, 446-452. http://doi.org/10.1016/j.chb.2014.04.011 
Steinfield, C., Ellison, N. B., \& Lampe, C. (2008). Social capital, self-esteem, and use of online social network sites: A longitudinal analysis. Journal of Applied Developmental Psychology, 29, 434-445. http://dx.doi.org/10.1016/j.appdev.2008.07.002

Subrahmanyam, K., Reich, S. M., Waechter, N., \& Espinoza, G. (2008). Online and offline social networks: Use of social networking sites by emerging adults. Journal of Applied Developmental Psychology, 29, 420-433. http://dx.doi.org/10.1016/j.appdev.2008.07.003

Sutcliffe, A. G., Dunbar, R. I. M., Binder, J., \& Arrow, H. (2012). Relationships and the social brain: Integrating psychological and evolutionary perspectives. British Journal of Psychology, 103, 149-168.

Tong, S. T., Van Der Heide, B., Langwell, L., \& Walther, J. B. (2008). Too much of a good thing? The relationship between number of friends and interpersonal impressions on Facebook. Journal of Computer-Mediated Communication, 13,531-549. http://dx.doi.org/10.1111/j.1083-6101.2008.00409.x

Trepte, S., Dienlin, T., \& Reinecke, L. (2015). Influence of social support received in online and offline contexts on satisfaction with social support and satisfaction with life: A longitudinal study. Media Psychology, 18, 74-105. http://dx.doi.org/10.1080/15213269.2013.838904

Uchino, B. N. (2006). Social support and health: A review of physiological processes potentially underlying links to disease outcomes. Journal of Behavioral Medicine, 29, 377-387.

Valkenburg, P. M., \& Peter, J. (2007). Preadolescents’ and adolescents’ online communication and their closeness to friends. Developmental Psychology, 43(2), 267277.

Walther J.B. and Boyd S., (2002), Attraction To Computer-Mediated Social Support. In C. A. Lin \& D. Atkin (Eds.), Communication technology and society: Audience adoption and uses (pp. 153-188). Cresskill, NJ: Hampton Press.

Wellman, B., \& Gulia, M. (1999). Net surfers don't ride alone: Virtual communities as communities. In M. A. Smith \& P. Kollack (Eds.), Communities in cyberspace (pp. 167194). Berkeley, CA: University of California Press.

Wellman, B., \& Wortley, S. (1990). Different strokes from different folks: Community ties and social support. American Journal of Sociology, 96, 558-588.

Wellman, B., Haase, A. Q., Witte, J., \& Hampton, K. (2001). Does the internet increase, decrease, or supplement social capital? American Behavioral Scientist, 45, 436-455. 
Wright, K. B., \& Bell, S. B. (2003). Health-related support groups on the Internet: Linking empirical findings to social support and computer-mediated communication theory. Journal of Health Psychology, 8, 39-54.

Wright, K. B., \& Miller, C. H. (2010). A measure of weak-tie/strong-tie support network preference. Communication Monographs, 77, 500-517.

http://dx.doi.org/10.1080/03637751.2010.502538

Wright, K. B., Rains, S., \& Banas, J. (2010). Weak-tie support network preference and perceived life stress among participants in health-related, computer-mediated support groups. Journal of Computer-Mediated Communication, 15, 606-624. http://dx.doi.org/10.1111/j.1083-6101.2009.01505.x

Zhang, Y \& Leung, L, (2015) A review of social networking service (SNS) research in communication journals from 2006 to 2011. New Media \& Society, 17(7), 1007-1024. 